\title{
Polystyrene as a zwitter resist in electron beam lithography based electroless patterning of gold
}

\author{
T BHUVANA and G U KULKARNI* \\ Chemistry and Physics of Materials Unit and DST Unit on Nanoscience, \\ Jawaharlal Nehru Centre for Advanced Scientific Research, Bangalore 560 064, India
}

\begin{abstract}
The resist action of polystyrene $\left(M_{\mathrm{w}}, 2,600,000\right)$ towards electroless deposition of gold on Si(100) surface following cross-linking by exposing to a $10 \mathrm{kV}$ electron beam, has been investigated employing a scanning electron microscope equipped with electron beam lithography tool. With a low dose of electrons $\left(21 \mu \mathrm{C} / \mathrm{cm}^{2}\right)$, the exposed regions inhibited the metal deposition from the plating solution due to cross-linking-typical of the negative resist behaviour of polystyrene, with metal depositing only on the developed Si surface. Upon increased electron dosage $\left(160 \mu \mathrm{C} / \mathrm{cm}^{2}\right)$, however, Au deposition took place even in the exposed regions of the resist, thus turning it into a positive resist. Raman measurement revealed amorphous carbon present in the exposed region that promotes metal deposition. Further increase in dosage led successively to negative $\left(220 \mu \mathrm{C} / \mathrm{cm}^{2}\right)$ and positive $\left(13,500 \mu \mathrm{C} / \mathrm{cm}^{2}\right)$ resist states. The zwitter action of polystyrene resist has been exploited to create line gratings with pitch as low as $200 \mathrm{~nm}$ and gap electrodes down to $80 \mathrm{~nm}$.
\end{abstract}

Keywords. Electron resist; electroless deposition; gold patterning.

\section{Introduction}

In the last two decades, electron beam lithography (EBL) has emerged as an important tool to produce raised patterns of metals, semiconductors and polymers as well as reticular structures (Tseng et al 2003). In EBL, a substrate coated with an electron sensitive material is exposed to a fine pencil of energetic electrons that is being steered to write a desired pattern. The pattern is transferred to a metal (or any desired material) by etching or lift off depending on whether metal was deposited prior to or following the developing of the resist. EBL is capable of generating patterns down to $10 \mathrm{~nm}$ but the throughput is rather poor. It is, therefore, used as a specialty tool to produce masks and master patterns for further use in other lithographic techniques such as optolithography (Thompson et al 1994; Russell et al 2006) and microcontact printing (Biebuyck et al 1997; Xia et al 1999).

Over the years, several chemical formulations, mostly polymers, have been tried out as e-resists. Upon electron beam exposure, a polymeric resist undergoes chain scission (positive resist) or cross-linking (negative resist) and the exposed regions exhibit enhanced (positive) or diminished (negative) solubility in a chosen solvent. Polymethyl methacrylate (PMMA) is being routinely used as a positive e-resist to produce reticular patterns with $1: 1$ isopropanol:methylisobutylketone as a developer (Bernstein et al 1992). Other examples include PBS (polybu-

*Author for correspondence (kulkarni@jncasr.ac.in) tene-1-sulfone), EBR-9 (a copolymer of trifluoroethyl $\alpha$ chloroacrylate and tetrafluropropyl $\alpha$-chloroacrylate), ZEP (a copolymer of chloromethacrylate and methylstyrene) as well as polyphenol-based resists. Similarly, negative resists such as P(GMA-EA), an epoxy copolymer of glycidyl methacrylate and ethylacrylate, also known as COP, CMS (a partially chloromethylated polystyrene), EPR (epoxidized novolac resist) as well as calixarene and its derivatives are being used to produce raised patterns. Interestingly, some resists exhibit a switching behaviour, from positive to negative or vice versa, upon prolonged exposure of the electron beam (Chen et al 2005). Zailer et al (1996) and Hoole et al (1997) found PMMA behaving as a positive resist below an electron dose of $30 \mu \mathrm{C} \mathrm{m}^{-1}$ to change to a negative behaviour upon an additional dose of $\sim 50-70 \mu \mathrm{C} \mathrm{m}^{-1}$. Geis et al (1985) reported the positive and negative self-developing resist behaviour of nitrocellulose on exposure of heavy ions $\left(\mathrm{Ar}^{+}\right)$. Tada and Kanayama (2000) found the negative-positive tone resist behaviour of derivatives of triphenylene. Seki et al (1997) reported the positive-negative inversion of silicon-based resist such as poly(di- $n$-hexylsilane) upon ion beam irradiation. Of late, even inorganic resists have been reported to exhibit zwitter resist action (Chuang et al 2006).

In this paper, we show the results of our investigations on the resist behaviour of polystyrene coated on Si substrates. Following developing of the patterned resist, $\mathrm{Au}$ metal deposition was achieved by the electroless plating method from a solution consisting of $0.1 \mathrm{mM}$ potassium tetrachloroaurate in $5 \mathrm{M} \mathrm{HF}$. The evolving nature of the resist towards the electroless process was studied as a 
function of the e-dosage. Our experiments have shown that the resist behaviour of polystyrene with respect to electroless plating does depend on the extent of electron dosage, showing a zwitter behaviour, negative to begin with. By suitably programming the electron beam, we have been able to obtain Au line grating patterns and gap electrodes as well as other nanostructures on the patterned substrate.

\section{Experimental}

The procedure is shown schematically in figure 1. Initially, $\mathrm{Si}(100)$ substrates ( $n$-doped, 4-7 ohm cm) were cleaned by sonicating in acetone followed by doubly distilled water and were dried under flowing argon. A $1 \%$ solution of polystyrene $\left(M_{\mathrm{w}}, 2,600,000\right)$ in toluene was spin coated (3000 rpm, $60 \mathrm{~s}$ ) on the substrate to form a thin film. Polystyrene of a higher molecular weight was preferred due to its enhanced sensitivity (Imamura et al 1982; Khoury and Ferry 1996). The film thickness was measured using a Wyko NT1100 (Veeco, USA) optical profiler (OP). The PSI mode was employed with a field of view and objective lens magnifications as $1 \mathrm{X}$ and $20 \mathrm{X}$, respectively. Electron beam lithography (EBL) was performed using a FEI Nova NanoSEM 600 equipment (The Netherlands). The desired regions of the resist coated substrate was

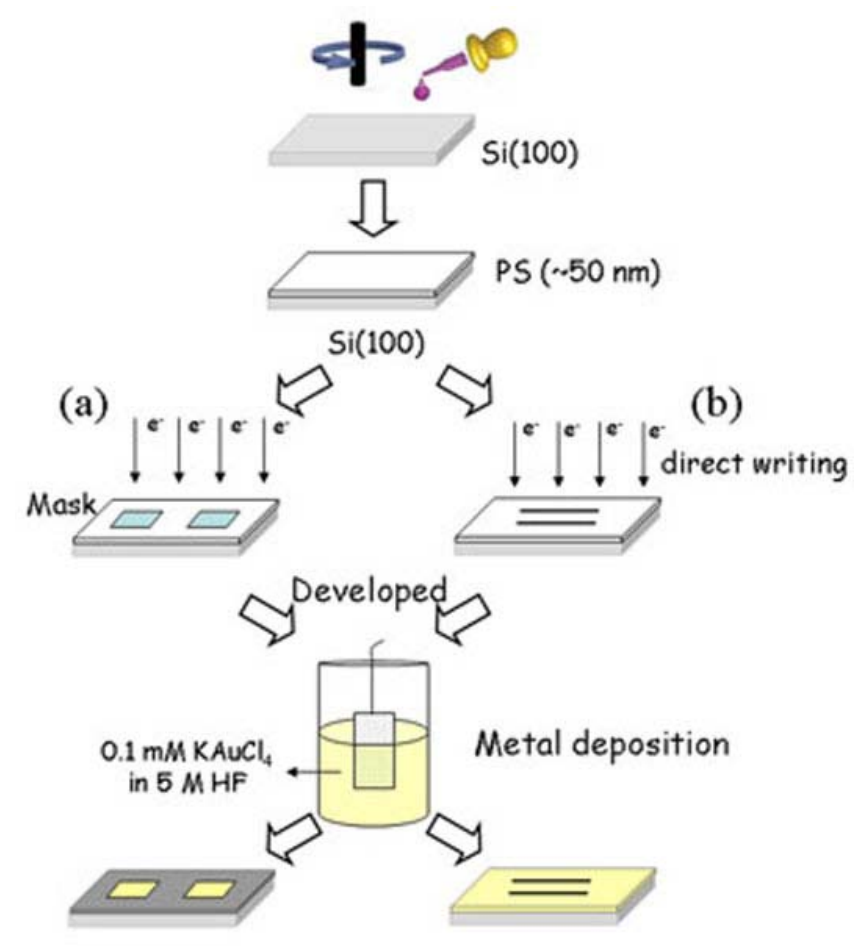

Figure 1. Schematic of the procedure adopted for electron beam lithography (EBL). The polymer (polystyrene) coated substrate was patterned with e-beam with mask (a) or by direct write method (b). The e-beam exposed substrate was developed and $\mathrm{Au}$ metal was deposited by electroless method. exposed to either a broad electron beam while masking using a TEM grid or to a focused beam using the direct write method (see schematic in figure 1). After exposure to electron beam, the resist film was developed by dipping the substrate in $p$-xylene for $90 \mathrm{~s}$ and 2-propanol for $30 \mathrm{~s}$ (Austin et al 2005) and dried under flowing argon. The unexposed regions were washed off leaving behind the crosslinked polymeric pattern. Thus exposed Si surface was deposited with $\mathrm{Au}$ by an electroless method. The plating solution consisted of $0.1 \mathrm{mM} \mathrm{KAuCl}_{4}$ in $5 \mathrm{M} \mathrm{HF}$ held in a teflon container. Energy dispersive spectroscopic (EDS) mapping was performed using EDAX Genesis V4.52 (USA) attached to the SEM column. Raman measurements have been carried out on the exposed resist using a LabRam equipment with a He-Ne laser source $(631.8 \mathrm{~nm})$ and a spot size, $\sim 1 \mu \mathrm{m}$.

\section{Results and discussion}

Figure 2 shows the SEM images of the direct write patterns. Squares were drawn on the polymer coated Si substrates with $10 \mathrm{kV}$ as electron beam energy but with different dosages. Figure 2 a contains an image of a region $\left(11 \times 13 \mu \mathrm{m}^{2}\right)$ seen with a dark contrast that was exposed with $21 \mu \mathrm{C} / \mathrm{cm}^{2}$, resulting in cross-linking of the polymer resist. The region surrounding the dark square is relatively bright and accordingly, the EDS spectrum (also shown in the figure) showed the presence of Au metal. In contrast, the EDS spectrum from the dark region showed only the presence of carbon. Thus, the cross-linked region inhibits the metal deposition, while the surrounding region contained unexposed resist that got washed away during developing thus exposing the Si surface for metal deposition. This result demonstrates the usual negative resist behaviour of polystyrene. For convenience, we denote the $\mathrm{Au} / \mathrm{Si}$ region (in figure $2 \mathrm{a}$ ) as 0 state and the cross-linked region as $1(\mathrm{~N})$ state where, in anticipation of several states of the resist, 1 stands for the first state with $\mathrm{N}$ representing the negative behaviour.

In figure $2 b$ is shown a region $\left(250 \times 220 \mu \mathrm{m}^{2}\right)$ of the substrate exposed with an increased dosage of $160 \mu \mathrm{C} / \mathrm{cm}^{2}$ followed by electroless plating. Although electron exposed region is discernible, the contrast between the two regions is considerably less compared to that in figure $2 \mathrm{a}$. Accordingly, the EDS measurements showed the presence of Au metal in both the regions. Clearly, with an electron dosage of $160 \mu \mathrm{C} / \mathrm{cm}^{2}$, the polymer reached a state beyond cross-linking and allowed metal uptake from the plating solution. We denote this second state as $2(P)$, $P$ representing the positive resist behaviour.

When the electron dosage was increased to $220 \mu \mathrm{C} / \mathrm{cm}^{2}$ (figure 2c), interestingly, the metal uptake in the exposed region is negligible somewhat resembling the case in figure 2a. With the increased electron dosage to $220 \mu \mathrm{C} / \mathrm{cm}^{2}$, the polymer switches its behaviour to negative tone that 

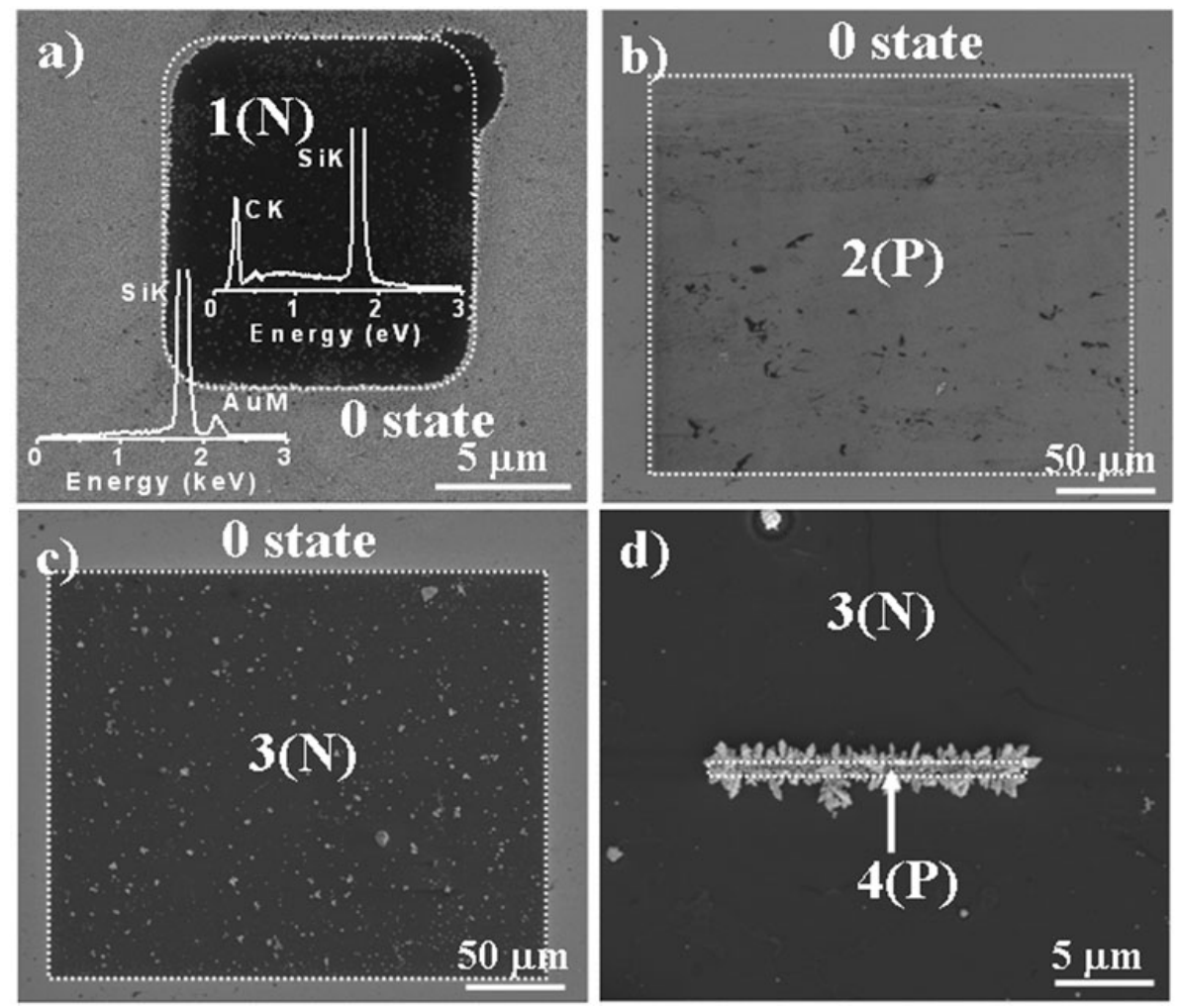

Figure 2. SEM images of the patterned substrate. The dashed line marks the region subjected to electron beam exposure. (a) A $11 \times 13 \mu \mathrm{m}^{2}$ region dosed with $21 \mu \mathrm{C} / \mathrm{cm}^{2}$. The EDS spectrum from the outside region shows the presence of $\mathrm{Au}$ metal, while that from inside shows only carbon, (b) a $250 \times 220 \mu \mathrm{m}^{2}$ region with a dosage of $160 \mu \mathrm{C} / \mathrm{cm}^{2}$, (c) a $250 \times 220 \mu \mathrm{m}^{2}$ region dosed with $220 \mu \mathrm{C} / \mathrm{cm}^{2}$ and (d) further dosed with $13500 \mu \mathrm{C} / \mathrm{cm}^{2}$ in the centre $(15 \mu \mathrm{m}$ line). Here, $P$ and $N$ denote the positive and negative tone behaviour of the polystyrene resist while the numbers indicate the successive states.

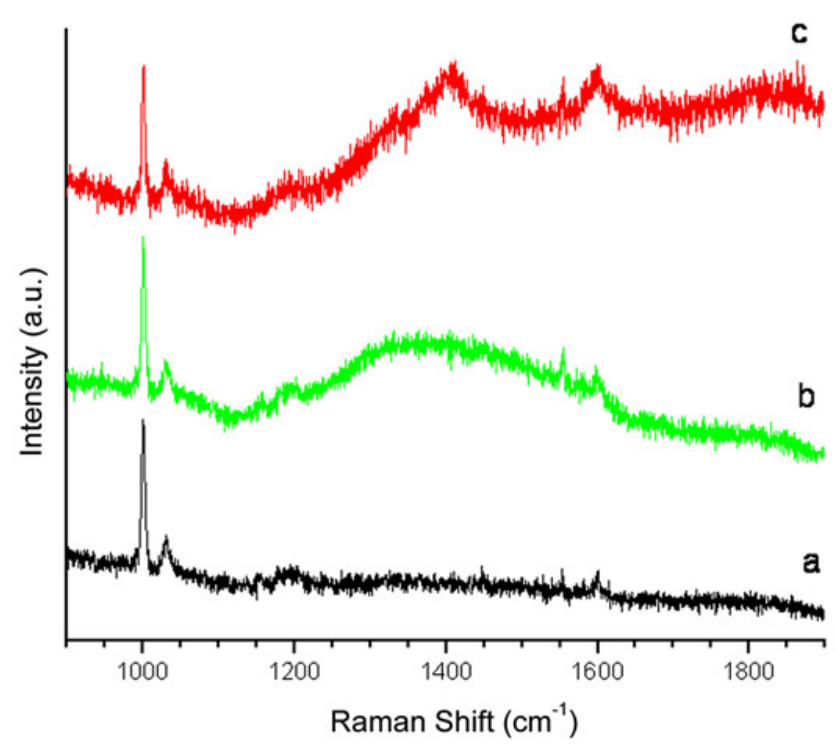

Figure 3. Raman spectrum of polystyrene in (a) the pristine form, (b) 2(P) state and (c) $3(N)$ state.

is denoted as $3(N)$ state. A narrow line region within the $3(N)$ region was exposed to $13500 \mu \mathrm{C} / \mathrm{cm}^{2}$ at $30 \mathrm{kV}$ that perhaps removed the resist altogether allowing the metal uptake in the exposed Si region. This may be denoted as $4(P)$ state.

More insight into the resist behaviour particularly the $2(P)$ and $3(N)$ states, was obtained by carrying out Raman measurements. Figure 3 shows the Raman spectra in the range $900-1900 \mathrm{~cm}^{-1}$, obtained for the different states corresponding to different electron beam dosages. We observe bands at 999 and $1020 \mathrm{~cm}^{-1}$ arising from $\mathrm{C}-\mathrm{C}$ ring deformation (Choi and Kertesz 1997). In spectrum ' $a$ ' from the pristine polymer film, we observe a small band around $1585 \mathrm{~cm}^{-1}$ corresponding to ring $\mathrm{C}-\mathrm{C}$ stretching, more of $s p^{2}$ nature. The spectrum ' $b$ ' from the $2(P)$ region (see figure $2 \mathrm{~b}$ ) contains, in addition, a broad band centred around $1350 \mathrm{~cm}^{-1}$. This may be a signature of disordered carbon that is likely to form when a cross-linked polymer is further exposed to the electron beam. Incidentally, amorphous carbon on Si promotes Au uptake (Bhuvana et al 2007), thus making it effectively a positive resist in our experiment. The spectrum ' $c$ ' from the $3(N)$ region shows two relatively sharp bands at 1380 and $1560 \mathrm{~cm}^{-1}$. These may be taken to represent more crystalline state of the carbon (Ferrari and Robertson 2000) resulting from an 


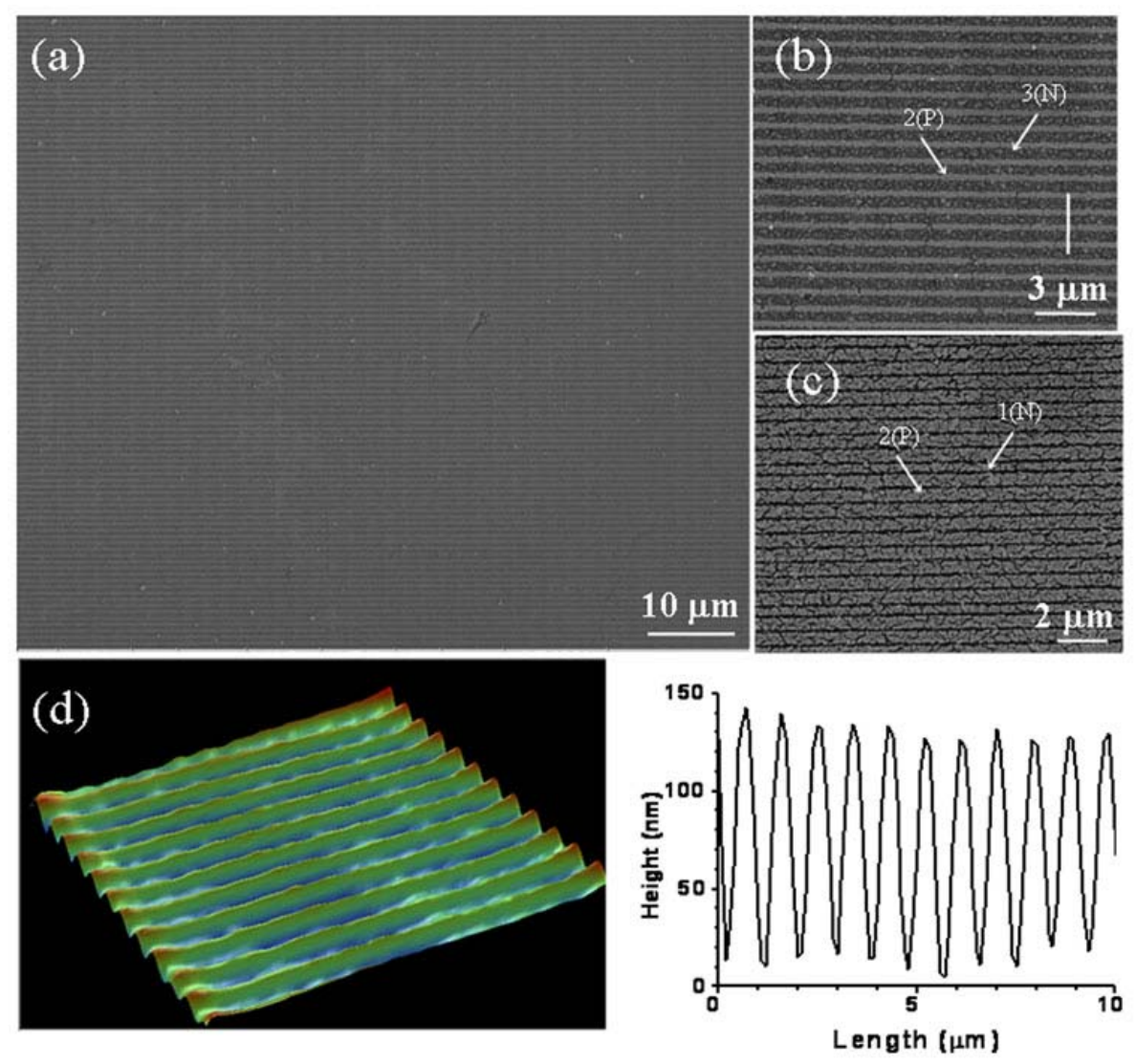

Figure 4. (a) Line grating pattern generated by switching between $2(P)$ and $3(N)$ states with its magnified image in (b), (c) line grating pattern generated by switching between 0 and $1(N)$ states and (d) an optical profilometric image of the gratings in (a) with the measured profile.
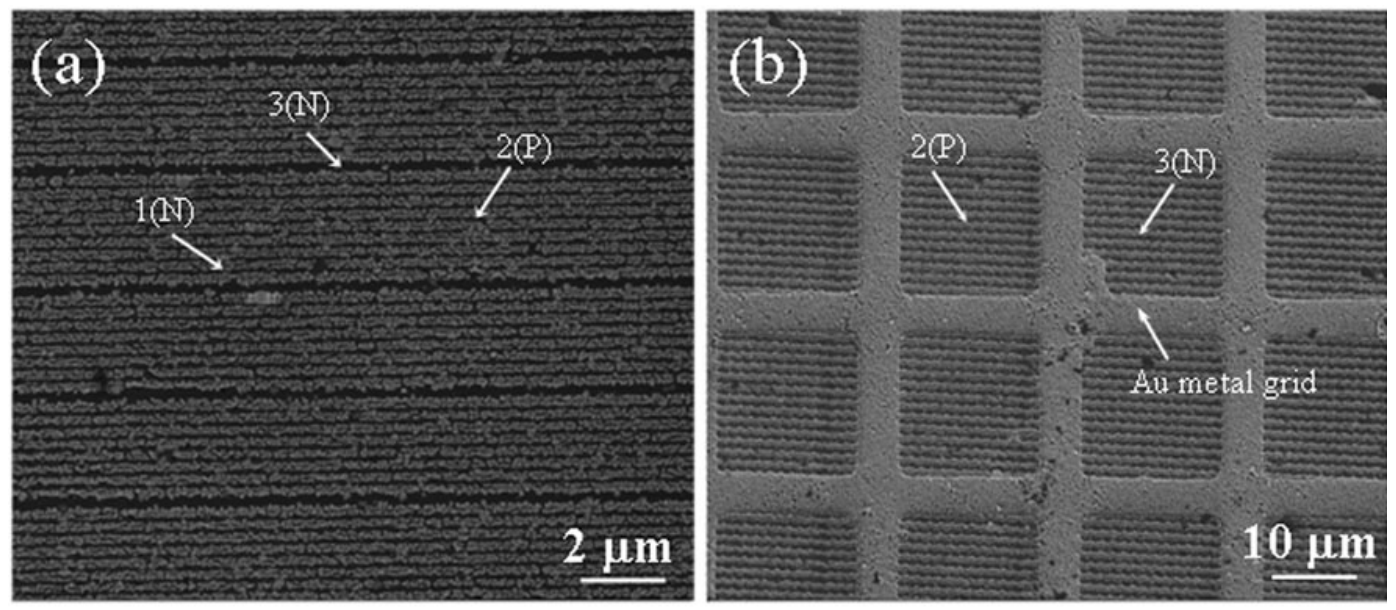

Figure 5. A modulated grating pattern generated (a) with two different pitches, $350 \mathrm{~nm}$ and $2.9 \mu \mathrm{m}$ and (b) using a TEM Cu-grid as an additional mask during e-dosage.

excessive electron dosage. Crystalline carbon on Si being relatively inactive in the electroless process, gives rise to a negative tone behaviour.

Having understood the zwitter action of the polystyrene resist in electroless plating, we could arrive at appropriate conditions for patterning $\mathrm{Au}$ on $\mathrm{Si}$. In figure 4 are shown $\mathrm{Au}$ line gratings obtained by electroless $\mathrm{Au}$ deposition on a developed pattern from the direct write method. Figure 4a contains line gratings with a pitch of $750 \mathrm{~nm}$ obtained using electron beam energy, $5 \mathrm{kV}$, with 

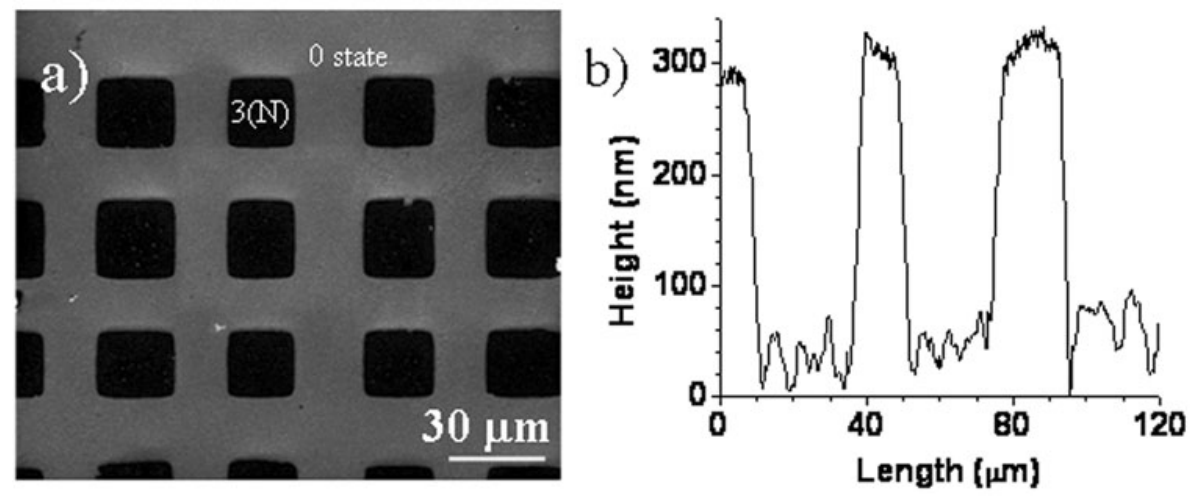

Figure 6. (a) Au metal wells generated by masking the resist film with a TEM Cu-grid and exposing to a broad beam and (b) height profile is shown alongside.

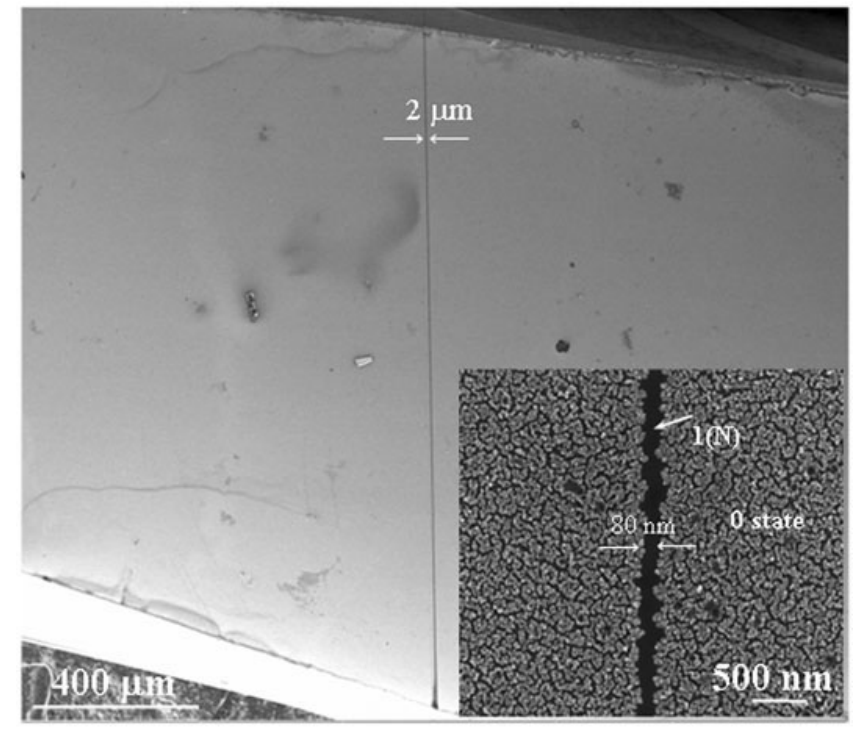

Figure 7. A 'quick circuit' generated by drawing a single line with the electron beam across a $\mathrm{Si}$ substrate coated with the resist. Au deposition following developing of the resist produced a gap of $\sim 2 \mu \mathrm{m}$. Inset shows a gap electrode with a separation of $\sim 80 \mathrm{~nm}$.

electron dosage of $200 \mu \mathrm{C} / \mathrm{cm}^{2}$. Under the given exposure conditions, Au lines of $230 \mathrm{~nm}$ width are created with the $2(P)$ behaviour of the resist with the gap $(500 \mathrm{~nm})$ corresponding to the $3(N)$ state. By decreasing the electron beam dosage to $10 \mu \mathrm{C} / \mathrm{cm}^{2}$, one can also create periodic line spacings $(\sim 120 \mathrm{~nm})$ in the $1(N)$ state, with metal depositing in between ( $300 \mathrm{~nm}, 0$ state) (see figure $4 \mathrm{c}$ ). In figure $4 \mathrm{~d}$ is shown a $3 \mathrm{D}$ profilometric image of the gratings along with the height profile. The measured pitch from the profile is found to be $780 \mathrm{~nm}$, similar to that seen in figure $4 \mathrm{~b}$. With the direct write method, we have achieved patterning over a few $\mathrm{mm}$ square areas.

The zwitter behaviour of the polystyrene resist can be extended to produce more complicated patterns. Figure 5 shows SEM images of such line gratings. The line grating structure in figure $5 \mathrm{a}$ was obtained by first patterning the resist working between 0 and $1(N)$ states (similar to that in figure 4c) followed by another exposure with a periodicity of $2.9 \mu \mathrm{m}$ to result in the $3(N)$ state. Following developing and metal deposition, the modulated structure shown in the figure emerges. In figure $5 \mathrm{~b}$ is shown a set of line gratings obtained working between $2(P)$ and $3(N)$ states (similar to figure $4 \mathrm{~b}$ ) while additionally masking with a TEM Cu-grid. The electron beam can also be programmed to create uniformly a $3(N)$ state in the exposed regions. An extended deposition in the plating solution (120 min) produced a well-defined metal grid structure on the substrate (figure 6). A profile analysis revealed the depth of the wells to be $\sim 300 \mathrm{~nm}$ (figure $6 \mathrm{~b}$ ). Such microwells may find applications in microfluidics.

It may be noted that the metal deposited electrolessly is in intimate contact with the Si substrate. Thus, a combination of EBL and electroless process can potentially produce nanometric patterned electrodes for electric field induced embossing and pattern transfer. While such studies are in progress in our laboratory, here we have shown how quick line scans followed by developing and electroless Au deposition can produce gap electrodes. The SEM image in figure 7 contains a $2 \mu \mathrm{m}$ gap electrode extending across a $2 \mathrm{~mm}$ long Si substrate, bisecting it into two macroscopic contact pads. The inset in figure 7 depicts the image of another set of electrodes with $\sim 150 \mathrm{~nm}$ separation. Importantly, such gap electrodes can be produced in a matter of few seconds. This method of producing gap electrodes is more suited for high conducting nanomaterials, since in the absence of an insulating oxide layer underneath, the gap resistance itself is not too high $(\sim 10 \mathrm{ohm} \mathrm{cm})$.

The chosen resist being very sensitive to the electron beam, an extended exposure may sometimes lead to cracks in the film exposing the Si underneath. The SEM images in figure 8 show an interesting crack propagation across the resist film. In figure 8a, the bright lines represent the cracked regions, filled with Au during plating. A EDS mapping of the Au M line confirmed this observation (see figures $8 b$ and $c)$. 

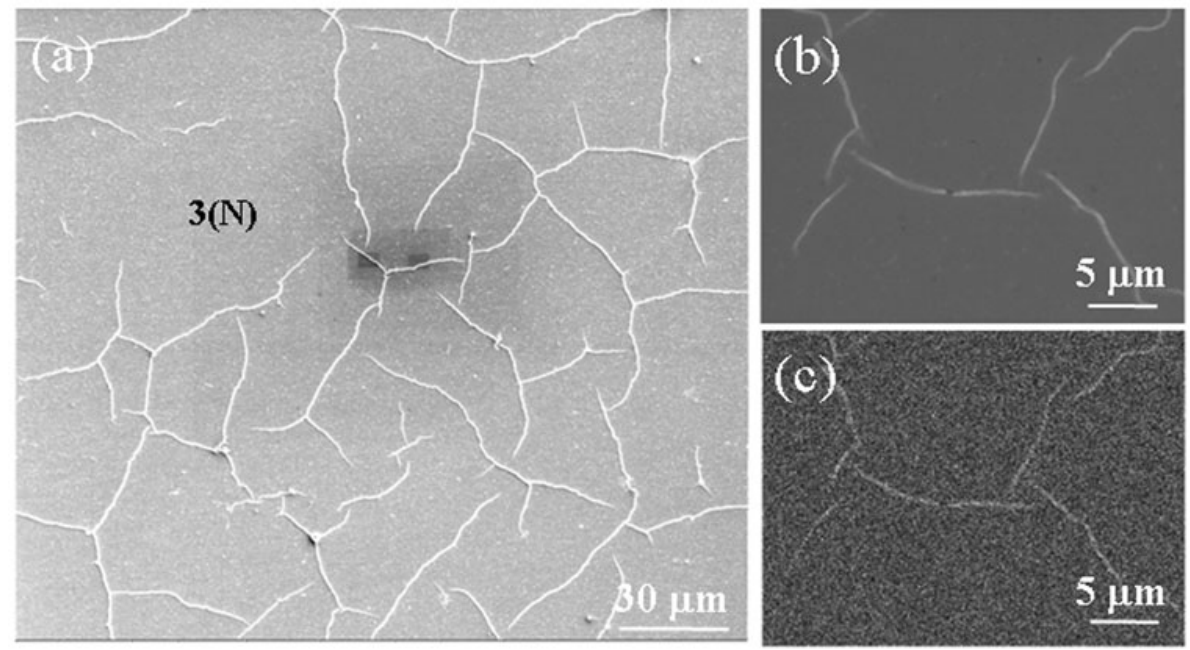

Figure 8. A cracked resist film upon prolonged exposure to the electron beam. (a) Crack propagation showing an interesting pattern, Au M line EDS mapping of a selected region (b), shown in (c) reveals Au deposition in the cracked regions.

\section{Conclusions}

We have shown the zwitter resist action of polystyrene during electroless deposition of gold. While increasing the electron dosage from $20 \mu \mathrm{C} / \mathrm{cm}^{2}$ to several thousand units, polystyrene initially behaving as a negative resist, exhibits successive positive and negative states. Raman spectroscopy measurements on the electron beam exposed regions showed that the cross-linked polymer forms amorphous carbon at dosages of $\sim 150 \mu \mathrm{C} / \mathrm{cm}^{2}$, and becomes crystalline upon further dosage (above $200 \mu \mathrm{C} / \mathrm{cm}^{2}$ ). The amorphous state of carbon allows electroless metal deposition while the crystalline state inhibits, thus bringing out the zwitter action of the resist. Line gratings have been generated with the lowest pitch value being $200 \mathrm{~nm}$. Similarly, gap electrodes with separation below $100 \mathrm{~nm}$ have been fabricated. More intricate patterns such as microchannels have also been produced for applications in microfluidics.

\section{Acknowledgements}

The authors thank the Department of Science and Technology, Government of India, for research grants. They thank Professor C N R Rao for valuable discussions and gratefully acknowledge his constant support and encouragement. They also thank Mr S R C Vivekchand and Ms Gomathi for the Raman measurements.

\section{References}

Austin M D, Zhang W, Ge H X, Wasserman D, Lyon S A and Chou S Y 2005 Nanotechnology 161058
Bernstein G H, Hill D A and Liu W 1992 J. Appl. Phys. 71 4066

Biebuyck H A, Larsen N B, Delamarche E and Michel B 1997 IBM Res. Develop. 411 Y 97

Bhuvana T, Kumar G V P, Narayana C and Kulkarni G U 2007 Nanotechnology 18145702

Chen J-K, Ko F-H and Chang F-C 2005 Adv. Funct. Mater. 15 1147

Choi C H and Kertesz M 1997 J. Phys. Chem. A101 3823

Chuang C-M, Wu M-C, Huang Y-C, Cheng K-C, Lin C-F, Chen Y-F and Su W-F 2006 Nanotechnology 174399

Ferrari A C and Robertson J 2000 Phys. Rev. B61 14095

Geis M W, Randall J N, Mountain R W, Woodhouse J D, Bromley E I, Astolfi D K and Economou N P 1985 J. Vac. Sci. Technol. B3 343

Hoole A C F, Welland M E and Broers A N 1997 Semicond. Sci. Technol. 121166

Imamura S, Tamamura T, Harada K and Sugawara S $1982 \mathrm{~J}$. Appl. Polym. Sci. 27937

Khoury M and Ferry D K 1996 J. Vac. Sci. Technol. B14 75

Russell M T, Pingree L S C, Hersam M C and Marks T J 2006 Langmuir 226712

Seki S, Kanzaki K, Yoshida Y and Tagawa S 1997 Jpn J. Appl. Phys. 365361

Tada T and Kanayama T 2000 Microelectronic Engineering 53 425

Thompson L F, Willson C G and Bowden M J 1994 Introduction to microlithography (Washington, DC: American Chemical Society) 2nd ed.

Tseng A A, Chen K, Chen C D and Ma K J 2003 IEEE Transactions on Electronics Packing Manufacturing 26141

Xia Y, Rogers J A, Paul K E and Whitesides G M 1999 Chem. Rev. 991823

Zailer I, Frost J E F, Chabasseur-Molyneux V, Ford C J B and Pepper M 1996 Semicond. Sci. Technol. 111235 